\title{
CARACTERIZAÇÃO E ESTUDOS DE CREPITAÇÃO DE UM MINÉRIO DE MANGANÊS DA REGIÃO DE DOM SILVÉRIO-MG*
}

\author{
Bárbara Dornelas de Assis ${ }^{1}$ \\ Érica Linhares Reis ${ }^{2}$ \\ Guilherme Henrique Ferreira Olivares Solis ${ }^{3}$ \\ Anderson Silveira Lopes 4
}

\section{Resumo}

Minérios de manganês são uma importante fonte de matéria-prima para a siderurgia. Desse modo, o desenvolvimento de trabalhos de caracterização para melhor compreensão da composição e o comportamento desses minérios é de suma importância. O presente trabalho teve como objetivo a caracterização física, química, mineralógica e a análise do comportamento de crepitação do produto granulado de minério de manganês de uma mina da região de Dom Silvério no estado de Minas Gerais. Cerca de $77 \%$ do produto granulado encontra-se entre 50 e $6,3 \mathrm{~mm}$. O minério de manganês é composto pelas fases minerais manganita, pirocroita, groutelita, birnessita, siderofilita e calcopirita. Os teores dos elementos majoritários $\mathrm{Mn}$, $\mathrm{Fe}$ e $\mathrm{SiO}_{2}$ foram, respectivamente, 24,04\%, 8,89\% e 15,57\%. A densidade estrutural da amostra é de $3,25 \mathrm{~g} / \mathrm{cm}^{3}$ e sua área superficial, $6,8 \mathrm{~m}^{2} / \mathrm{g}$. O ensaio de crepitação realizado mostrou que o índice desse fenômeno para a amostra com umidade natural é de $8,82 \%$ e se encontra próximo dos índices de crepitação de minérios de manganês atualmente comercializados no Brasil. A secagem da amostra não reduziu de forma significativa os índices de crepitação no minério.

Palavras-chave: Minério de manganês; Caracterização; Crepitação; Ferro ligas de manganês.

\section{CHARACTERIZATION AND DECREPTATION STUDIES OF A MANGANESE ORE OF DOM SILVÉRIO-MG REGION}

\section{Abstract}

Manganese ores are an important source of raw material for ferromanganese alloys. Thus, the development of characterization work to better understand the composition and behavior of these ores is of paramount importance. This study aimed to the physical, chemical, mineralogical and analysis of the granulated product decreptation behavior of a manganese ore from a mine Dom Silverio region in the state of Minas Gerais. About $77 \%$ of the granulated product is between 50 and $6.3 \mathrm{~mm}$. Manganese ore is composed of the mineral phases manganite, pyrochroite, groutellite, birnessite, siderophyllite and chalcopyrite. The amounts of the major elements $\mathrm{Mn}, \mathrm{Fe}$ and $\mathrm{SiO}_{2}$ were, respectively, $24.04 \%, 8.89 \%$ and $15.57 \%$. The structural density of the sample is $3.25 \mathrm{~g} / \mathrm{cm}^{3}$ and a surface area $6.8 \mathrm{~m}^{2} / \mathrm{g}$. The decreptation test conducted showed that the index of this phenomenon in the sample to the natural humidity is $8.82 \%$ and is close to sputter rates of manganese ores currently marketed in Brazil. Drying did not reduce significantly the decreptation indexes in ore $(0.04 \%)$.

Keywords: Manganese ore; Characterization; Decreptation; Ferromanganese alloys.

1 Graduanda em Engenharia de Minas, Técnica em Mineração, Departamento de Engenharia de Minas/Escola de Minas, Universidade Federal de Ouro Preto, Ouro Preto, Minas Gerais, Brasil.

2 Professora, Doutora, Departamento de Engenharia de Minas/Escola de Minas, Universidade Federal de Ouro Preto, Ouro Preto, Minas Gerais, Brasil.

3 Graduando em Engenharia de Minas, Departamento de Engenharia de Minas/Escola de Minas, Universidade Federal de Ouro Preto, Ouro Preto, Brasil.

4 Engenheiro, Engenheiro de Processos, VALE/Manganês, Ouro Preto, Minas Gerais, Brasil. 


\section{INTRODUÇÃO}

Aproximadamente $90 \%$ de todo o manganês produzido no mundo está na forma de ferro ligas de manganês das quais pelo menos $98 \%$ são consumidas pela indústria do aço (1). Na produção das ferro ligas de manganês os minérios de manganês utilizados são, usualmente, definidos de acordo com as suas características químicas e granulométricas, sendo comum o desconhecimento a respeito das características mineralógicas e metalúrgicas dos granulados de minérios. Um parâmetro de qualidade importância, e ainda pouco estudado, é a crepitação. Minérios que apresentam alto valor de crepitação podem levar a perda de permeabilidade do forno, em menor eficiência das trocas térmicas e alterações da resistividade elétrica da carga, com consequentes prejuízos a produtividade do reator. Faria (2) desenvolveu um trabalho pioneiro com relação ao estudo de crepitação de diferentes categorias tipológicas de granulados de minérios de manganês do Brasil, assim como na aplicação de tratamentos térmicos que objetivavam minimizar a intensidade deste fenômeno. Mas, novas tipologias e pequenas minas produtoras de minérios de manganês vêm surgindo necessitando de novos estudos. Neste contexto, de forma a viabilizar melhoria no beneficiamento de novos minérios de manganês que vem sendo comercializados e o processo metalúrgico de fabricação de ferro ligas de manganês, este trabalho teve como objetivo desenvolver um estudo de caracterização do produto granulado de minério de manganês de uma pequena mineradora da região de Dom Silvério localizada em Minas Gerais.

\section{MATERIAIS E MÉTODOS}

Foi realizada a amostragem e homogeneização do produto granulado de minério de manganês de uma pequena mineradora localizada na região de Dom Silvério - MG. Qualitativamente foram determinadas as fases minerais por difratometria de raios- $\mathrm{X}$, pelo método do pó total. A análise granulométrica foi realizada por peneiramento a úmido utilizando peneiras da série Tyler. A densidade estrutural da amostra foi determinada pelo picnômetro a gás (hélio). As análises de área superficial específica e de porosidade foram realizadas pelo método de adsorção de nitrogênio (B.E.T). A determinação dos elementos majoritários que constituem a amostra global do produto granulado do minério de manganês foi realizada por ICP - OES. A metodologia e preparação das amostras destinadas aos ensaios de crepitação foram adaptadas da norma ISO 8731 e de Faria (2), e estes realizados em duplicata.

\section{RESULTADOS E DISCUSSÃO}

Na Figura 1 está apresentada a curva de análise granulométrica do granulado de minério de manganês da região de Dom Silvério - MG. 


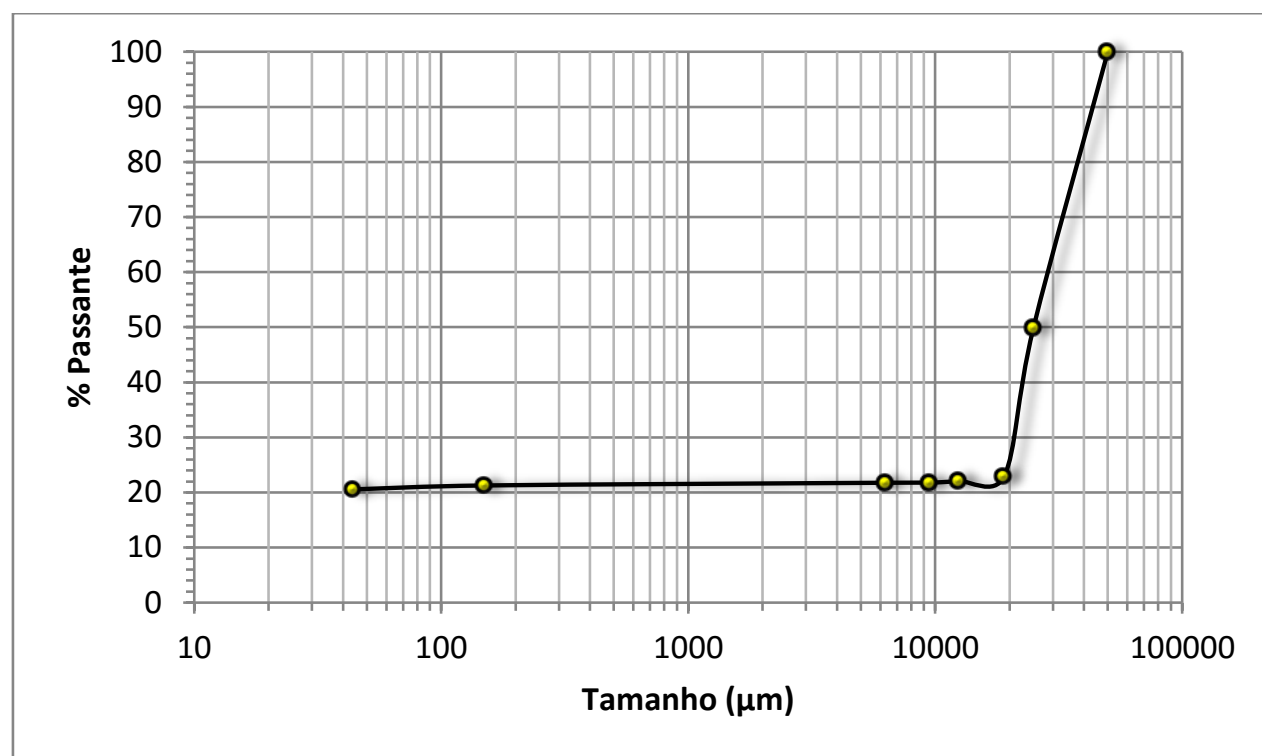

Figura 1 - Curva da análise granulométrica da amostra de granulado de minério de manganês da região de Dom Silvério.

De acordo com a curva de análise granulométrica (Figura 1), do produto granulado em estudo, o valor de d80 é igual a $40,0 \mathrm{~mm}$. Isto significa que $80 \%$ do material está abaixo desta granulometria. Nota-se que cerca de $77 \%$ do material se encontra com a granulometria entre 50,0 e $6,3 \mathrm{~mm}$. Apenas $0,5 \%$ do material se encontra na granulometria de sínter feed $(-6,3 \mathrm{~mm}+0,150 \mathrm{~mm})$, e cerca de $1 \%$ na granulometria de pellet feed $(-0,150 \mathrm{~mm}+0,044 \mathrm{~mm})$, ou seja, a maior porcentagem do material encontra-se dentro da faixa granulométrica esperada, denominado produto granulado.

Existem mais de 300 espécies minerais que contém manganês em sua composição e que podem ocorrer sob a forma de óxidos, hidróxidos, silicatos e carbonatos (1). Os principais minerais identificados por difratometria de raios $X$ no produto granulado de minério de manganês estudado, estão classificados e acompanhados de suas respectivas fórmulas químicas na Tabela 1. O produto granulado é composto majoritariamente por hidróxidos de manganês e minerais de ganga.

Tabela 1. Principais minerais de manganês e de ganga identificados no granulado de minério de manganês da região e Dom Silvério - MG

\begin{tabular}{|c|c|c|}
\hline Mineral & Classe & Fórmula Química \\
\hline Manganita & Hidróxido & $\mathrm{MnO}(\mathrm{OH})$ \\
\hline Pirocroita & Hidróxido & $\mathrm{Mn}(\mathrm{OH})_{2}$ \\
\hline Grautita & Hidróxido & $\mathrm{H}_{0,5 \mathrm{MnO}_{2}}$ \\
\hline Birnessita & Óxido & $\mathrm{H}_{3} \mathrm{Mnn}_{2} \mathrm{Na}_{0.58} \mathrm{O}_{5.5}$ \\
\hline Siderofilita & Silicatos & $\begin{array}{c}\mathrm{H}_{0.25} \mathrm{Al}_{1.88} \mathrm{~F}_{1.25} \mathrm{Fe}_{1.02} \mathrm{~K}_{0.97} \mathrm{Li}_{0.65} \mathrm{Mg}_{0.08} \\
\mathrm{Mn}_{0.08} \mathrm{Na}_{0.02} \mathrm{O}_{10.75} \mathrm{Si}_{3.13} \mathrm{Ti}_{0.05}\end{array}$ \\
\hline Calcopirita & Sulfetos & $\mathrm{CuFeS}_{2}$ \\
\hline
\end{tabular}

A análise química determinou os teores dos elementos majoritários, que estão apresentados na tabela 2 . 
Tabela 2. Teores dos elementos na amostra no granulado de minério de manganês da região de Dom Silvério - MG

\begin{tabular}{|c|c|c|c|c|c|c|c|c|c|}
\hline \multicolumn{10}{|c|}{ Teores (\%) } \\
\hline Amostra & $\mathbf{M n}$ & $\mathbf{F e}$ & $\mathrm{SiO}_{2}$ & $\mathbf{A l}$ & $\mathbf{B a}$ & $\mathbf{C a}$ & $\mathbf{M g}$ & $\mathbf{P}$ & $\mathbf{T i}$ \\
\hline $\begin{array}{c}\text { Produto granulado de } \\
\text { minério de Mn }\end{array}$ & 24,04 & 8,89 & 15,57 & 7,5 & 0,599 & 0,296 & 0,099 & 0,106 & 0,342 \\
\hline
\end{tabular}

A análise química da amostra global do granulado de minério de manganês para os elementos $\mathrm{Mn}$, $\mathrm{Fe}$ e $\mathrm{SiO}_{2}$, foram 24,04; 8,89 e 15,57\% e o produto granulado não se encontra dentro do limite indicado nas especificações químicas (Mnmínimo - 23\%, Femáximo $-6 \%$ e $\mathrm{SiO} 2 m a ́ x i m o-35 \%)$. A relação $\mathrm{Mn} / \mathrm{Fe}$, importante dado para os minérios de manganês utilizados na indústria metalúrgica, está fora das especificações para esta aplicação (relação ideal $\mathrm{Mn} / \mathrm{Fe} \geq 7$, mas 0 valor 6 é aceitável).

Analisando-se individualmente a porcentagem de manganês, a tipologia estudada neste trabalho se classifica como um minério do tipo ferruginoso, por possuir o teor de manganês entre 15 e $35 \%$ (1).

Tabela 3. Classificação dos minérios de manganês em função do teor de manganês(1)

\begin{tabular}{|c|c|}
\hline Classificação & Teor de $\mathbf{M n}(\%)$ \\
\hline Minério de Manganês & $\mathrm{Mn}>35$ \\
\hline Minério Ferruginoso & $15<\mathrm{Mn}<35$ \\
\hline Minério de Ferro Manganesífero & $5<\mathrm{Mn}<10$ \\
\hline
\end{tabular}

A tabela 4 apresenta os resultados relacionados à área superficial, densidade estrutural e volume de microporos, obtidos pela técnica de B.E.T. para as amostras na faixa de 19 a 6,3mm comparados aos obtidos por Faria (2).

Tabela 4. Área superficial, densidade estrutural e volume de microporos calculados na amostra pelo BET (Método de Adsorção de Nitrogênio), na faixa de 19 a 6,3mm

\begin{tabular}{|c|c|c|c|}
\hline $\begin{array}{c}\text { Produto } \\
\text { Granulado }\end{array}$ & $\begin{array}{c}\text { Área superficial } \\
\left(\mathbf{m}^{\mathbf{2}} \mathbf{g}\right)\end{array}$ & $\begin{array}{c}\text { Densidade } \\
\text { estrutural }\left(\mathbf{g} / \mathbf{c m}^{\mathbf{3}}\right)\end{array}$ & $\begin{array}{c}\text { Volume de } \\
\text { microporos }\left(\mathbf{c m}^{\mathbf{3}} \mathbf{g} \mathbf{g}\right)\end{array}$ \\
\hline $\begin{array}{c}\text { Mina da região de } \\
\text { Dom Silvério }\end{array}$ & 6,8 & 3,25 & 0,033 \\
\hline Mina do Azul $^{[2]}$ & 12,3 & 4,02 & 5,229 \\
\hline $\begin{array}{c}\text { Mina de Morro da } \\
\text { Mina }^{[2]}\end{array}$ & $\mathbf{1 , 2}$ & 3,66 & 0,513 \\
\hline Mina de Urucum $^{[2]}$ & $\mathbf{4 , 4}$ & 4,41 & 2,426 \\
\hline
\end{tabular}

A área superficial do minério granulado de Mn se mostrou mais próximo dos maiores valores identificados por Faria (2). O valor de densidade estrutural é mais aproximado ao da Mina de Morro da Mina, em Minas Gerais. Em relação ao volume de microporos, este se encontrou bem abaixo das tipologias dos outros depósitos. $O$ valor de densidade relativa do granulado de minério de manganês ficou em torno de $3,3 \mathrm{~g} / \mathrm{cm}^{3}$. 
O resultado do teste de perda por calcinação, indica a porcentagem de perda de massa da amostra, que ficou em torno de a 3,5\%. A tabela 5 fornece os valores dos índices de crepitação para as amostras à umidade natural comparados aos de Faria (2) em seus estudos sobre as tipologias dos principais depósitos de manganês do Brasil.

Tabela 5. Índices de crepitação da amostra à umidade natural, na faixa de $-19+6,3 \mathrm{~mm}$

\begin{tabular}{|c|c|c|}
\hline Amostras $(-19 \mathrm{~mm}+6,3 \mathrm{~mm})$ & $\begin{array}{c}\text { Crepitação } \\
\text { (<6,3mm) } \\
(\%)\end{array}$ & $\begin{array}{c}\text { Desvio } \\
\text { Padrão (\%) }\end{array}$ \\
\hline Mina da região de Dom Silvério & 8,8 & 0,56 \\
\hline Mina do Azul ${ }^{[2]}$ & 10 & 3 \\
\hline Mina de Morro da Mina ${ }^{[2]}$ & 0,5 & 0,5 \\
\hline Mina de Urucum ${ }^{[2]}$ & 16 & 4 \\
\hline
\end{tabular}

Quando comparados a granulados estudados por Faria (2) o produto granulado de minério de manganês da pequena mineradora localizada na região de Dom SilvérioMG possui o índice de crepitação (8,8\%) intermediário, não tão baixo quanto 0 granulado da Mina Morro da Mina, mas também não tão alto quanto o de Urucum. Com valor próximo ao do granulado da Mina do Azul. O valor de microporosidade do produto granulado, em estudo, é muito menor que o identificado para outros granulados caracterizados por Faria (2). Os produtos granulados com os maiores valores de microporosidade foram os que apresentaram os maiores valores de crepitação.

Na Tabela 6 estão apresentados os resultados de crepitação obtidos neste trabalho e no trabalho de Faria (2) para o produto granulado das principais minas de minérios de manganês do Brasil após processo de secagem. Para o produto granulado em estudo o índice de crepitação não reduziu, significativamente, após a secagem em relação ao seu valor à umidade natural. Essa diminuição foi apenas de 0,09\%. Já Faria (2) obteve valores consideráveis de redução nos índices de crepitação dos minérios de seu estudo.

Tabela 6. Índices de crepitação da amostra após secagem $\left(100 \pm 5 C^{\circ}\right)$, na faixa de $-19+6,3 \mathrm{~mm}$

\begin{tabular}{|c|c|c|}
\hline Amostras (-19mm +6,3mm) & $\begin{array}{c}\text { Crepitação } \\
(<6,3 \mathrm{~mm})(\%)\end{array}$ & $\begin{array}{c}\text { Desvio } \\
\text { Padrão (\%) }\end{array}$ \\
\hline Mina da região de Dom Silvério & 8,73 & 0,83 \\
\hline Mina do Azul $^{2]}$ & 6 & 2 \\
\hline Mina de Morro da Mina $^{[2]}$ & 0,5 & 0,5 \\
\hline Mina de Urucum $^{[2]}$ & 10 & 5 \\
\hline
\end{tabular}


As amostras secas apresentaram pouca diminuição nos índices de crepitação, o que significa que a umidade presente neste minério tem pouca influência sobre a degradação do mesmo durante o aquecimento nos fornos de redução, parecendo sim estar relacionado a decomposição das fases minerais hidratadas que constituem o produto granulado. Os resultados indicaram que os índices de crepitação se encontraram próximos dos índices de minérios de manganês atualmente comercializados no Brasil.

\section{CONCLUSÃo}

- Cerca de $77 \%$ da amostra de granulado de minério de manganês encontra-se dentro da especificação granulométrica;

- Os minerais de manganês foram manganita, pirocroita e grautita enquanto os minerais de ganga foram birnessita, siderofilita e calcopirita;

- Os teores de $\mathrm{Mn}, \mathrm{Fe}$ e $\mathrm{SiO}_{2}$ foram respectivamente, 24,04\%, 8,89\% e 15,57\% e não está dentro dos limites indicados nas especificações químicas, pois o teor de ferro se encontra acima do limite máximo permitido ( $\mathrm{Mn}_{\text {mínimo }}-23 \%$,

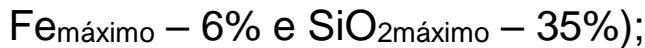

- O índice de crepitação do minério com sua umidade natural foi de $8,8 \%$, e após secagem, 8,73\%. Portanto, a secagem do granulado de minério de manganês da região de Dom Silvério não diminui o resultado da crepitação.

\section{Agradecimentos}

Os autores agradecem a Fundação Gorceix, FAPEMIG, CNPq e VALE/Manganês.

\section{REFERÊNCIAS}

1 OLSEN, S.E; TANGSTAD,M; LINDSTAD, T. Production of Manganese Ferroalloy. Tapir academic Press. Trondheim, Norway. 2007; 247p.

2 FARIA GL. Estudo da intensidade de crepitação de minérios granulados de manganês do Brasil Dissertação (Mestrado em Engenharia de Materiais). 2008; 61-107. 